\title{
An Exploration of Classroom Practices in Secondary Schools
}

\section{OPEN ACCESS}

Volume: 7

Issue: 4

Month: September

Year: 2019

P-ISSN: 2320-2645

Received: 01.08.2019

Accepted: 20.08.2019

Published: 01.09.2019

Citation:

Choudhury, Mehnaz

Tazeen. "An Exploration

of Classroom Practices

in Secondary Schools."

Shanlax International

Journal of English, vol. 7, no. 4, 2019, pp. 1-10.

DOI:

https://doi.org/10.34293/

english.v7i4.621

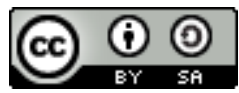

This work is licensed under a Creative Commons AttributionShareAlike 4.0

International License

\author{
Mehnaz Tazeen Choudhury \\ Associate Professor, Department of English, University of Asia Pacific, Dhaka, Bangladesh
}

\begin{abstract}
This study was undertaken in the secondary schools of Dhaka, Bangladesh. Students from Bengali medium schools of Bangladesh do not achieve even a minimal amount of proficiency in English even after completing high school. Moreover, they are seen to remain teacher dependent even at tertiary level. Learner autonomy is seen as a crucial need of the time in the context of Bangladesh. Obviously either classroom practices or teacher beliefs, or both are responsible for this state of affairs. Therefore, it became imperative to conduct a research to find out the classroom practices of English language teachers and see whether they were autonomy supportive. This was an exploratory qualitative research and the participants were class VII English language teachers from five government and non-government Bengali medium schools. Classroom observations and semi-structured interviews were used to collect the data. Findings of this study has implications for teacher training programmes and how they need to be redesigned to bring about a change in teacher beliefs and approaches.
\end{abstract}

Keywords: Classroom Practices, Learner Autonomy, Teacher Beliefs.

\section{Context of the Study}

The political history of Bangladesh has had a strong impact on the quality of English language teaching in the country. In the immediate aftermath of the liberation of the country, public sentiment precluded the desire to give importance to any language other than their own. However, while the nation's history was taking such a significant turn, the English language was fast gaining the status of a lingua franca in a world rapidly moving towards globalization.. The result of the renewed emphasis on Bangla in all aspects of life led to a steady decline in the quality of English language teaching.

The situation has reached a point that students of mainstream Bengali medium schools gain little proficiency in the language even though they start learning English from nursery level. Not only that, these students remain dependent on their teachers even at tertiarylevel. This research was propelled by the need to understand why it is that students cannot become autonomous language learners even though their extrinsic motivation to do so is a strong one.

In today's world the need to be lifelong learners is very important. Therefore, it is important that pupils become autonomous learners in all spheres and specially in English language learning. It is all the more necessary in Bangladesh, because being a monolingual country, students here get no exposure to the language in their everyday life. So the need to promote learner autonomy in language learning remains a strong one. Teachers have a huge role to play in nurturing learner autonomy because learners need to be taught how to become autonomous. Therefore, keeping in mind that learner autonomy should be the objective of language teaching, it became necessary to explore the classroom practices of language teachers to find out what it was that was impeding students' ability to learn the language. 
The study was done on secondary school teachers because students need to be taught to take the responsibility for their learning from as early as school level to become autonomous learners.

\section{Theoretical Underpinnings}

This study drew on Vygotsky's constructivism and Deci and Ryan's Self Determination Theory (1985).According to the theory of constructivism, "knowledge cannot be taught but must be constructed by the learner" (Candy as cited in Benson, 2001, p. 35). Constructivists emphasize the importance of a learning environment where students can discover their own meaning of the knowledge that they acquire through dialogue and reflection rather than have their teachers impart it to them. So a constructivist teacher is one who "empowers his/her students and increases their motivation and ability to develop through questioning and objection" (Aviram, 2000, p. 466). Hence the process of learning must be such that the capacity to control one's own learning activities is fostered in them. This is central to the theory of autonomy.

Self- Determination theory, a theory of human motivation posited by Deci and Ryan in 1985 (as cited in Deci \& Ryan, 2008) is based on the hypothesis that humans have certain psychological needs which have to be satisfied for them to remain psychologically healthy. This theory has an integral role in the field of education (Niemiec\& Ryan, 2009 , p. 134) because it focuses on those human characteristics "that either facilitate or forestall the assimilative and growth- oriented processes in people".

\section{Review of Literature}

In a formal, and institutional educational system, it is the teacher who has to develop the learner's capacity to become autonomous. To do so, teachers need to create opportunities in the classroom for learners to take charge of their learning, by encouraging reflection, by creating a collaborative learning environment, and raising awareness.

In defining autonomy Henry Holec (1981, p. 3) underscored several areas in which learners need to take charge of their learning:
- determining objectives

- defining the content and progressions

- selecting methods and techniques to be used

- monitoring the procedure of acquisition

- evaluating what has been acquired

Holec's definition of learner autonomy, however is not a simple process that can be easily implemented because in a traditional classroom it is difficult to give autonomy to students in all the above mentioned areas of learning. However, fostering autonomy requires that the teacher should work round the constraints, and create opportunities for the learners to determine the objectives and content of the lessons in a way which helps them make meaning out of their own world view.

In linking the data to all the aspects of an autonomous classroom, the setting of objectives, defining the content and evaluating or self-monitoring have been included. However it was felt that it is not possible for students to be given autonomy in the aspects of selecting the techniques and methods of learning, and monitoring the procedure of acquisition in the context of secondary school institutional learning. Therefore, it was felt it would be more apt to investigate whether learners were being made aware of different learning strategies, both cognitive and meta-cognitive, as these help students to pick and choose how they can learn best and also enable them to monitor their own progress.

\section{Methodology \\ Design}

The present study was essentially an exploratory qualitative one and the findings were reported in a narrative account.

\section{Research question}

This research aimed at gaining an understanding of the classroom practices of secondary school English language teachers of Bangla medium schools in Dhaka, the capital of Bangladesh. The study sought to find out the answer to the following question:

Were the classroom practices of English language teachers autonomy supportive in secondary schools?

It was understood that teachers may not have been cognizant with the term autonomy but they 
may still have been fostering it in their classroom. So the study explored whether the different teaching practices used by teachers conformed to those practices that help learners to formulate their own learning strategies and become autonomous.

\section{Sample}

Purposive sampling was used to decide who the participants would be.The sample size was not too large because the objective was to get comprehensive information and therefore, the focus was on depth rather than the breadth of information. To procure in depth data for qualitative analysis, ten class 8 English teachers, two each from five schools were chosen.

Out of the five schools, one was a government school and four were autonomous institutions. The number of students in the schools ranged from approximately 1500 to 2000 . The number of teachers varied from 55 to 100 .

\section{Research Tool and Procedure}

The data collection involved classroom observations and open ended interviews of the teachers who were observed. Asemi-structured classroom observation schedule was used to collect data. The structured section of the schedule provided data on the observable areas of inquiry, and a narrative report ensured that aspects which were not part of the schedule could also be included. Six classes of the same teachers were observed. The teachers were interviewed after the classroom observations were over. The interviews were semi-structured and were designed to get clarity on certain classroom behavior as well as insights into teacher beliefs.

\section{Findings and Analysis}

A grounded method of analysis was used to analyze the qualitative data from classroom observations and the interviews to find out what patterns emerged from there. The classroom behavior of teachers, including the type of language they used for specific instructions were calculated manually after listening to the transcripts. This added to the notes taken during the observations. Data from the interviews were triangulated to validate the findings from both the research tools.
To foster autonomy, students should be involved in the decision of what their learning objectives should be. However, Reinders has noted that, learners usually do not have any notion of what their language needs may be nor are they aware of their own weaknesses in terms of those needs" (2010, p. 46). A study by Allison Hoffmann (1999) with students of an undergraduate ESL course established that a dialogue between teachers and learners can enable learners to identify their goals but it is not enough to enable them to achieve those goals. The findings of Hoffmann's study also indicated that the dialogue "initially, needs to be more teacherdirected" (Hoffmann, 1999, p. 137) with students with a lower proficiency level. Schunk and Ga (as cited in Hoffmann, 1999, p. 127-128) view goal setting not just as a beginning of the course activity but rather an ongoing process.

Teachers in this study usually entered the classroom and told students what the day's lesson would be. No dialogues were held either to decide on the long term or the short term learning goals. They were not seen to involve students in any kind of dialogue with the students. Dialogue has been cited as one of the fundamental prerequisites to the fostering of autonomy. Classroom observations revealed that students were not invited to share their opinion about what they would like to learn in the next class or what they felt they had learnt after a particular lesson. Even certain tasks that were given to students were not discussed with them. Homework was usually given in a hurry with no prior discussion at the end of class time. Teachers usually used words like:

"Quickly, write down your home-work ..."

"Write the HW in your diary."

"Now here's your HW (wrote on board)...note it down."

No feedback on homework were observed to have been provided in any class in any form.

An autonomy supportive teacher lets her students choose a different task with the same learning objectives if they show unwillingness to do a certain lesson. This was also not observed to take place in any of the classes. However, in answer to an interview question the participants asserted that they gave importance to what the students wanted. 
A majority responded that they could not follow their lesson plans because of consideration for their students. The following are a few of their answers:

"... sometimes we have to cope with the students' needs".

"...it's not done in the classroom... students are the main factor."

"Actually, sometimes I am driven by my students, ... I try to meet their demands."

The fact that teachers said that they were guided by their students would indicate that some kind of dialogue took place between them and their learners. However, in practice this was not the case. Students were not asked to share their opinions on anything.

So even though the interview responses revealed teacher beliefs to conform to the concept of autonomy, their teaching practices revealed a total lack of autonomy supportive behavior.There was an apparent mismatch between teacher beliefs and practices in this case.

The interview responses also indicated that teachers did not really believe that their students were competent enough to give useful opinions pertaining to their learning. This belief manifested itself in their classroom practices when they failed to discuss with their learners the lessons they should be doing or the objectives of the lessons that they did do.

It is important in an autonomous classroom for learners to have access to a variety of texts and materials. Texts should have a variety of subjectmatter and different levels from which to choose from. This can help in a mixed ability class. Moreover, the tasks should be such that learners should have the scope to think about them and come up with their own interpretations of them, thus developing their ability to think critically and to reflect on what they read. In traditional schools, however, text books are prescribed by the education board written to the specification of the curriculum or sometimes by the school itself.

Under such conditions, it was understandable, when eight out of 10 teachers said that they were expected to complete the syllabus within a specified time, and had time constrains. Moreover, there was pressure on them from the administration to complete the syllabus, and ensure good results in the state examinations. Therefore, it was not possible for them to use anything outside the prescribed text books. But, teachers could find a way around their constraints if they reflected on the issue. Amritavalli (2013), at a presentation at the Teacher Education Conference (TEC 13), Hyderabad suggested that teachers need to experiment in the class to see what works with their students and how they react to their textbooks. She asserts that "even a prescribed textbook can be taught in a way that encourages learner autonomy" (Amritavalli, 2012, p. 3). Her study with a very low proficiency group of students from a disadvantaged background showed that those students preferred to read stories and poems from their own textbooks rather than use outside materials. Passing the examination was theirmain objective. The findings of her study indicated that a learner can be given the autonomy to choose even if it is to choose a part of the prescribed textbook that is relevant to his needs, and appeals to him.

Interview responses revealed that teachers did not have the time to use materials from outside mainly because covering all the chapters in the textbook was a priority. When asked how they would prepare students for the unseen comprehension that was to be introduced in the Junior Secondary Certificate examinations from that year, teachers did not express much concern. They said they would think about using passages from other books only if they had time to do it after completing the textbook.

In an autonomous classroom, self- evaluation is "viewed as the pivot of a good learning/ teaching cycle" (Dam, cited in Dam and Legenhausen, 1999, p. 90) . An autonomous learner is necessarily one who is constantly monitoring and evaluating his own learning. It is seen as a continual classroom process undertaken by the teacher and learners alike. It was not clear whether teachers in this study were aware of this aspect of evaluation. Even though teachers did not involve students in self-evaluation they did involve them in peer correction. This was observed for a total of 44 times across 60 classes. This was also the most prominent of autonomy supportive practices among teachers across all schools. This gave students the control over their learning in the sense that they could reiterate their learning through correcting each other, and in the process learn from each other. This practice was probably not because 
teachers wanted to empower students but, because, in a large classroom, getting students to orally correct each other during oral lessons ensured that teachers could get an idea of the amount of learning that had taken place. Teachers used questions like:

Do you think $\mathrm{X}$ has written a correct sentence?

Who can write this sentence correctly?

Is the answer right?

The enthusiasm with which students pointed out the mistakes, and came up with the correct answers made it evident that this was common practice in these classrooms. At times students corrected each other even before the teacher asked them to.

However, teachers guided their students to correct their own mistakes only eight times in 60 classes. There were even times when the teacher asked students to sit down after he/she had answered incorrectly, instead of correcting them. When a few times, teachers did help students they reminded students of what they had read earlier in order to correct themselves. For instance

"What's the tense of the question? You should always use the tense of the question..."

"Just think for a moment whether this answer is right or wrong ... what is the subject...?"

"Have you written am/is/are? ... ok, just make it right."

Mainly teachers were non autonomy supportive in this aspect.

One significant point that was noted in the observations was that students were not taught to write essays or compositions. When asked about it, the teachers' answers revealed that they did not think writing was something they had to teach. They were apparently not aware that writing is a skill that needs to be taught. Apart from that, for students to become autonomous learners it is crucial that the learning environment promotes reflection and critical thinking. In the classes that were observed, such a learning environment was missing where learners could feel comfortable in using their own words to express their own opinions even if there were mistakes in their work. Students could not be expected to reflect over any topic unless they were encouraged to do so. These opportunities can be created in a syllabus oriented learning situation too. However, this practice was not observed in any of the classes. Students were asked to memorize answers and compositions for a total of 76 times across 60 classes as opposed to only seven times in the same number of classes where students were asked to use their own language. This behaviour of the teachers was totally non-autonomy supportive. Teacher expectations are shown through a few examples:

You just tell me the body of the application, loudly.

Where does Kartik plant trees? (this was from a comprehension passage)

All of you must memorize it - silently - start to memorize it. (This was an essay)

What is the structure of 3rd condition?

When teachers did ask students to use their own words, the instructions were mainly for essay, summary or paragraph writing to be done as homework with no guidelines given in class. There were no discussions on the topic, the required grammatical structure or the type of vocabulary they could use to successfully complete the task. Teachers used words like

Write a summary of the story "A man who loves trees", in your own words. [This was given as home work (HW)]. Write a paragraph about Shamima ... do it as your HW. Write it of (in) your own (words).

In response to an interview question regarding teacher expectations about memorized answers, however, eight out of 10 teachers said that students tended to memorize despite being told not to. Only one teacher said that he preferred that students should memorize. The tenth teacher had made her students memorize essays and e-mailsin all her observed classes so was not asked this question.. Teacher answers included

"Most of the topics they memorize. But I tell them not to memorize".

"...our students... - they prefer to memorize..."

"What they are supposed to do on their own, they don't...mostly they memorize."

Here again there was a mismatch between what was observed and what was said by the teachers. And their practices were seen to be totally non-autonomy supportive.

Another classroom practice which was seen as non-autonomy supportive was that teachers read out and explained texts and questions without initiating 
any discussions from students. This was observed 16 times in 31 comprehension classes. Teachers did not ask students to read or even try to find out if they had understood what had been read to them. Instead of encouraging students to understand the text or instructions by themselves they were being made teacher dependent by not being allowed to think for themselves. They used words like

"Match the sentences..." (teacher read out and explained entire question)

"Now I am going to tell about the Bengali meaning of this text."

"I am reading this text now, you listen carefully."

"Work in pairs and write ..." (teacher read and explained entire question)

According to Oxford, language learning strategies are "specific actions, behaviours, steps, or techniques that students (often intentionally) use to improve their progress in developing L2 skills" (1993).Learning strategies are essential tools for self-directed learning so it was crucial to find out if teachers helped students identify or use any strategies that could help them learn language on their own. Students need to be taught the importance of learning strategies and the use of different learning strategies needs to be incorporated in classroom tasks. Strategies instruction refers to teaching learners "how, when, and why strategies can be used to facilitate language learning and language use activities", while strategy integration refers to the process in which "strategies are integrated and embedded into classroom language activities to provide for contextualized strategy practice and reinforcement" (Cohen, 1999, p. 62-63).

Classroom observations revealed an apparent lack of instructions regarding learning strategies. Interview responses further revealed that teachers did not really know what learning strategies involve. When asked what language learning strategies they taught their students, some of their responses were

"Actually learning strategy is practice and participate... in various ways."

"I advise them to ...use different kinds of sources that means, radio, TV, newspaper, teacher class lecture."

"I tell them to practice at home whatever they have done in school."

"I advise them to share their - ideas, utterances with their parents, relatives, and everybody else in English..."
Teachers were not observed to encourage students to ask questions. They were observed to invite questions from students only 16 times across 60 classes. Teachers mostly explained and started asking questions without ensuring that everyone had understood. This practice should have been more frequent, and it was observed that students sometimes wanted to ask questions but the teacher had, by then, proceeded to another section of the lesson. There were times when students asked questions in spite of not being invited by the teacher to do so. This was autonomous learner behaviour.

Teachers were free with encouragements where they praised not only the students who answered correctly but also those who tried even if they were not correct. Encouragements can be very motivating. Praising students, offering encouragement and providing hints are three of 11 autonomy supportive practices identified by Reeve and Jang (2006, p. 211).

In oral classes, when teachers asked everyone to participate there was no compulsion, and only those students answered who wanted to. This was also regarded as autonomy supportive. A few examples of the words used by the teachers are given below:

"Don't hesitate to tell your answer...no problem if you are mistaken."

"If you try to write something you will be able to (do) it... if we don't make (mistakes) we will not be able to correct it."

"You have tried. Thank you for trying."

What was contradictory in the observations was that even though teachers were seen to be quite friendly and approachable and students also did not seem scared of their teachers, students were not comfortable expressing their views regarding their school work. The researcher found that it was not because students did not have anything to ask.

Another non-autonomy supportive practice that was observed was that all teacher student interactions were mostly in L1. The use of the L1 is not considered non autonomy supportive, but the fact that teachers did not encourage students to use the L2 or create an environment conducive to using the L2 is. Most of the time teachers used Bangla to explain the lessons and students also answered in their L1. Leni Dam (as cited in Little, 2009, p.154) posits that it is crucial 
for language teachers to use the target language with their learners and also ensure that learners use the same with each other also. David Little writes that, "if language learning depends crucially on language use, it follows that classroom communication must be organized so as to give learners access to a full range of discourse roles, initiating as well as responding" (Little, 2009, p.153). This is true, but SLA research has also established that the use of L1 in the L2 classroom has its advantages. In classrooms such as those in this study, the learners had very low proficiency in English and nothing could have been achieved if teachers used only the target language. According to Cook "dismissing the L1 out of hand restricts the possibilities for language learning" (2001, p. 405). Atkinson writes that the learners' "L1 can be a valuable resource if it is used at appropriate times and in appropriate ways" (as cited in Cole, 1998, para. 8). However, the ultimate aim of every language class should be the learner's ability to communicate in the target language. It was felt that the teachers in this study should have made more use of the target language together with the L1 so that students had increasing exposure to the spoken form enabling them to eventually use the language with ease. According to Paul Nation, the L1 of the learners plays a "small but important role" in communicating meaning and content but he writes that "Where learners have little opportunity to meet and use the L2 outside the classroom, it is very important that L2 use is maximised in the classroom." (2003, p. 2).

\section{Research findings have attributed the disparity between teacher beliefs and practices to}

(a) contextual factors such as a prescribed curriculum, time constraints, and high stakes examinations; (b) pulls and pressures between teachers' beliefs systems and subsystems (i.e. core vs peripheral beliefs); and (c) reverence and emotional attachments to traditional ways of teaching that they were exposed to when they were students. (Kumaravadivelu, 2012, p. 64)

It was observed that the first criterion actually applied to the situation of the teachers in this study. Teachers professed both time constraint to complete the syllabus and the pressures of high stakes examination as major reasons deterring them from making their teaching practices more effective. However, teachers also seemed intent on trying out what they had learned at different trainings sessions and tried to follow them. They seemed focused on trying to do exactly as they had been instructed at the training sessions. They seemed frustrated by the fact that despite their sincerest efforts they had been unable to apply their learning to their teaching situations even after making adaptations to fit their own classroom situations The training programmes obviously had not taken into consideration the constraints that are faced by most teachers of our schools. According to the instructions in the teachers' course book teachers were supposed to spend at least half an hour on each activity but class timings in schools did not exceed thirty to forty minutes. In spite of that, teachers, were seen to complete two to three activities in one class, giving little time to students to work out the answers themselves.

Teachers obviously gave no thought to the fact that if they helped their learners to work out some tasks on their own at the beginning of term it would enable the students to complete similar tasks by themselves later. Despite the constraints, there are always things a teacher can do to improve the teaching conditions. Teachers in this study did not reflect on what they could do to change the situation.

Thus, the analysis of the data showed that teaching practices in the language classrooms were mainly not autonomy supportive. There were a few practices which should have been fostering autonomy but they did not seem to have that effect. One can only surmise that the main reason behind students not becoming even a little autonomous could be because students were not allowed to think for themselves. There was no opportunity for them to reach their own understanding of the lessons through critical thinking. Even when students were given the freedom to choose whether they wanted to answer or not, or even when they were involved in peer correction, or teachers provided students the support to arrive at the correct answers, the answers that the teachers expected were usually memorized ones. So all that the learner had to do was recall what they had learnt earlier. When they were encouraged, they were not encouraged to think for themselves but rather to memorize better. Hence, it can be concluded that 
the teachers' approach to teaching and the teaching techniques they employed inhibited the nurturing of autonomy in the students.

Interview responses of teachers, however, revealed that they regretted that students were unable to learn the language but not one of the teachers thought that they needed to bring about a major change in their approach to teaching. A majority of them blamed the students for their lack of motivation. They said that teachers should use their own judgement on how to teach but their practices did not reflect that. Again their beliefs and practices did not match.

\section{Other Autonomy Inhibiting Factors}

The schools that were visited for this study were typical schools of the city. All of them had large, airy classrooms but the number of students was so high in each class that the classrooms seemed small. In three of the schools, when most of the students were present, there was shortage of seats. The average number of students in the observed classes was 66.7 and the average student attendance was54.48. Students had to keep their bags in front of them on their desks, and they kept their books and exercise books on top of their bags while reading or writing. The students sat on benches with four to six students sitting on each long bench. Ideally only three students could have been accommodated on each bench. Students sat so close together that it became difficult for them to write properly. This form of seating arrangement was not a good one as it made it difficult for teachers to reach all the students. Moreover, involving students in group work was next to impossible.

Teachers also had to cope with a great deal of disturbance from outside the classroom. Students would be having games classes or be moving from one class to another. There did not seem to be any rule in place to maintain silence in the corridors or outside classrooms. This again made it difficult for students to hear their teachers from the back. Moreover, it was observed that teachers were mostly teaching five to six classes daily. Teaching time was cut short because it took time for students to settle down, and sometimes time was lost trying to make room for all the students to sit. In discussing the findings and implications of this study, it is important that these factors are taken into account because they had a direct impact on the teaching practices of the teachers.

\section{Discussion}

The findings of this study broadly indicated that the teaching practices of English language teachers in secondary schools in Bangladesh were not very autonomy supportive. Under pressure from the administration to ensure that students performed well in the state held examinations, teachers taught to the test. In fact, teachers who were observed seemed unable to think beyond the examinations. Their main focus was to ensure that students were able to answer questions properly in the examinations. But English is not just a subject, it is a language and should be taught as such. Teachers did not show concerns about the fact that their learners were not gaining any proficiency in English despite getting good CGPAs. This approach to teaching English cannot, however, change very easily. The pressure for good results apparently comes not just from the administration but other stakeholders as well. The expectations of the stakeholders, and the conditions in which teachers have to teach, both combine to make it difficult for teachers to work around their constraints to teach in a way that learners can become more autonomous. In this type of educational environment where a teacher is considered good only if her students perform well in the board examinations, the teacher cannot feel very motivated to do anything but to teach to the test. Johnson rightly says that with "the oppressive nature of global educational policies and curricular mandates that hold teachers accountable for student learning based on standardized assessment instruments", it is not difficult to understand why L2 teachers find it difficult to give up the "teach-for-thetest mentality" (2006, p.248).

The importance given to examination results has given rise to the culture of memorization of answers. This in turn has given rise to the culture of coaching centres where 'knowing' teachers suggest questions that might come in the examinations and using of so-called "note-books' which provide answers to all possible questions that might be asked in the board examinations. This is so deeply rooted in the system 
that eradicating it would require a considerable change in examination policies and teaching practices. Without such a change it will be difficult to bring about any significant change in the approach towards language learning that teachers, learners and stakeholders have. To make matters worse the examination system and the text books do not match. The public examination system is a syllabus oriented one which encourages the grammar translation method of teaching whereas the textbook has been designed for communicative language teaching.

It must also be remembered that teaching beliefs of teachers emerge from their own learning experiences. Williams and Burden write that "a language teacher's horizons will be shaped in part by her own personal experiences, but also by traditional ways in which other language teachers throughout history have made sense of what it means to be a language teacher" (1997, p. 52). The teachers in this research had all studied under the same educational system. So it can be supposed that teachers who had themselves studied under the grammar translation method would find it more convenient to use the same method in their own teachings. However, interview responses revealed that the teachers wanted to adopt the communicative approach in their teaching practices and felt that their students would benefit from that approach if only they could employ it in their classes. The requirements of the examinations and the demands of the school administrators, however, prevented them from trying out anything new. Their frustration in this regard was evident from their interview responses. The teachers seemed to compromise between the constraints imposed by the expectations of good scores in the examinations and the new approaches to teaching that they were taught at the teacher training programmes. The findings reinforced that of a study conducted by Crookes and Arrakaki in 1999 which had concluded that the practices of overworked teachers often contradicted their beliefs primarily because they opted to do what was most convenient in their teaching situation. Hence, the mismatch between teacher beliefs and practices among the participant teachers.

\section{Implications of the Study}

The findings of this study makes it clear that teachers need to change their approach to teaching English. A teacher's understanding of what her role should be in the classroom shapes her belief about her students and her teaching practices. Teachers' beliefs that they are merely tools to ensure that students attain good results need to change if English is to be taught as a language. Teacher education obviously has an important role to play in bringing about a change in their approach to teaching but the traditional teacher training programmes where teachers are instructed on how to use the relevant text books are unlikely to change their beliefs. Teacher educators need to approach teacher training from a new perspective creating opportunities for teachers to reflect on their beliefs and critically evaluate their own approach to teaching. A healthy environment for dialogue and teacher collaboration needs to be ensured where teachers can share and learn from each other as well as from their educators. Unless teachers develop a critically reflective approach toward their teaching practices the situation in our language classes is unlikely to change.

\section{References}

Amritavalli, R. "Helping Children Become Readers." Language and Language Teaching, vol. 1, no. 1, 2012, pp. 1-4.

Aviram, A. "Beyond Constructivism: AutonomyOriented Education." Studies in Philosophy and Education, vol. 19, no. 1, 2000, pp. 465489.

Benson, P. Autonomy in language Learning, Pearson Education, Harlow, 2001.

Cohen, A.D. "Language Learning Strategies Instruction and Research." Learner Autonomy in Language Learning: Defining the Field and Effecting Change, edited by S. Cotterall and D. Crabbe, Peter Lang Publishing, Frankfurt, 1999, pp. 61-68.

Cole, S. "The Use of L1 in Communicative English Classrooms." The Language Teacher, vol. 22, no. $12,1998$.

Cook, V. "Using the First Language in the Classroom." The Canadian Modern Language Review, vol. 57, no. 3, 2001, pp. 402-423. 
Crookes, G and Arakaki, L. "Teaching idea sources and work conditions in an ESL program." TESOL Journal, vol. 8, no. 1, 1999, pp. 15-19.

Dam, L and Legenhausen, L. "Language acquisition in an autonomous learning environment: leaners' self-evaluations and external assessments compared." Learner Autonomy in Language Learning: Defining the Field and Effecting Change, edited by S. Cotterall and D. Crabbe, Peter Lang Publishing, Frankfurt, 1999, pp. 89-98.

Deci, E.L and Ryan R.M. "Self-Determination theory: A Macrotheory of Human Motivation, Development and Health." Canadian Psychology, vol. 49, no. 3, 2008, pp. 182-185.

Hoffmann, A. "Discourse Surrounding Goals in an Undergraduate ESL Class writing course." Learner Autonomy in Language Learning: Defining the Field and Effecting Change, edited by $\mathrm{S}$. Cotterall and D. Crabbe, Peter Lang Publishing, Frankfurt, 1999, pp. 127-138.

Holec, H. Autonomy and Foreign Language Learning, Pergamon Press, Oxford, 1981.

Johnson, K.E. "The Sociocultural Turn and Its Challenges for Second Language Teacher Education" TESOL Quarterly, vol. 40, no. 1, 2006, pp. 235-257.

Kumaravadivelu, B. Language Teacher Education for a Global Society, Routledge, New York, 2012 .

\section{Author Details}

Dr.Mehnaz Tazeen Choudhury, Associate Professor, Department of English, University of Asia Pacific, Dhaka, Bangladesh, Email ID: mehnazt.ch@uap-bd.edu.
Little, D. "Learner Autonomy, the European Language Portfolio and Teacher Development”. Maintaining Control: Autonomy and Language Learning, edited by R. Pemberton et al., Hong Kong University Press, Hong Kong, 2009, pp. 147-174.

Nation, P. "The role of the first language in foreign language learning." The Asian EFL Journal, 2003.

Niemiec, C.P. and Ryan, R.M. "Autonomy, Competence and Relatedness in the Classroom: Applying Self-Determination Theory to Educational Practice." Theory and Research in Education, vol. 7, no. 2, 2009, pp. 133-144.

Oxford, R. "Language learning strategies in a Nutshell: Update and ESL suggestions." TESOL Journal, vol. 2, no. 2, 1993, pp. 8-22.

Reeve, J and Jang, H. "What teachers say and do to support students' autonomy during a learning activity." Journal of Educational Psychology, vol. 98, no. 1, 2006, pp. 209-218.

Reinders, H. "Towards a Classroom Pedagogy for Learner Autonomy: A Framework of Independent Language Learning Skills." Australian Journal of Teacher Education, vol. 35 , no. 5, 2010, pp. 40- 55.

Williams, $\mathrm{M}$ and Burden, R.L. Psychology for Language Teachers: A Social Constructivist Approach, Cambridge University Press, Cambridge, 1997. 